\title{
The Inhibitory Effects of Forsythia Koreana Extracts on the Metastatic Ability of Breast Cancer Cells and Bone Resorption by Osteoclasts
}

\author{
Yu Li Kim ${ }^{1,2}$, Sun Kyoung Lee ${ }^{1}$, Kwang-Kyun Park ${ }^{1,2}$, Won-Yoon Chung ${ }^{1,2}$ \\ ${ }^{1}$ Department of Oral Biology, Oral Cancer Research Institute, BK21 PLUS Project, Yonsei University College of Dentistry, ${ }^{2}$ Department of Applied \\ Life Science, The Graduate School, Yonsei University, Seoul, Korea
}

\begin{abstract}
Background: Breast cancer is the most common malignant disease in women. The patients with advanced breast cancer develop metastasis to bone. Bone metastasis and skeletal-related events by breast cancer are frequently associated with the invasiveness of breast cancer cells and osteoclasts-mediated bone resorption. Forsythia koreana is used in oriental traditional medicine to treat asthma, atopy, and allergic diseases. The aim of this study was to evaluate the inhibitory effects of $F$. koreana extracts on the invasion of breast cancer cells and bone resorption by osteoclasts.

Methods: Cell viability was measured by an MTT assay and the migration and invasion of MDA-MB-231 cells were detected by a Boyden chamber assay. The formation of osteoclasts and pit was detected using tartrate-resistant acid phosphatase staining and calcium phosphate-coated plates, respectively. The activities of matrix metalloproteinases (MMPs) and cathepsin $\mathrm{K}$ were evaluated by gelatin zymography and a cathepsin $\mathrm{K}$ detection kit.

Results: The fruit and leaf extracts of $F$. koreana significantly inhibited the invasion of MDA-MB-231 cells at noncytotoxic concentrations. The fruit extract of $F$. koreana reduced the transforming growth factor $\beta 1$-induced migration, invasion and MMPs activities of MDA-MB-231 cells. In addition, the fruit, branch, and leaf extracts of $F$. koreana also inhibited the receptor activator of nuclear factor kappa-B ligand-induced osteoclast formation and osteoclast-mediated bone-resorbing activity by reducing the activities of MMPs and cathepsin K.

Conclusions: The extracts of $F$. koreana may possess the potential to inhibit the breast cancer-induced bone destruction through blocking invasion of breast cancer cells, osteoclastogenesis, and the activity of mature osteoclasts.
\end{abstract}

(J Cancer Prev 2016;21:88-94)

Key Words: Forsythia koreana, Breast neoplasm, Bone metastasis, Osteoclast, Bone resorption

\section{INTRODUCTION}

Bone metastasis frequently occurs in patients with metastatic breast cancer. ${ }^{1}$ Bone microenvironment is suitable for breast cancer metastasis because of various growth factors in bone matrix such as insulin-like factors, TGF- $\beta$, fibroblast growth factors, platelet-derived growth factors, and bone morphogenetic proteins. ${ }^{2,3}$ In normal bone, there is balance between osteoclasts which resorb bone and osteoblasts which form bone. Metastatic breast cancer cells secrete osteolytic factors, including parathyroid hormone-related protein, interleukin (IL)-6, IL-8, and IL-11. ${ }^{4}$ These factors stimulate osteoblasts or stromal cells to produce receptor activator of nuclear factor kappa-B ligand (RANKL) and inhibit decoy receptor osteoprotegerin. RANKL binds to RANK of osteoclasts precursors and induces osteoclast differentiation, causing bone resorption. ${ }^{5,6}$ The growth factors are released from bone matrix by bone resorption and promote breast cancer cell proliferation and secretion of osteolytic factors. ${ }^{7.8}$ Therefore, osteoclasts, as well as breast cancer cells, can be a strategic therapeutic target for breast cancer patients with bone metastasis. ${ }^{9,10}$

Received June 8, 2016, Accepted June 16, 2016

Correspondence to: Won-Yoon Chung

Department of Oral Biology, College of Dentistry, Yonsei University, 50-1 Yonsei-ro, Seodaemun-gu, Seoul 03722, Korea

Tel: +82-2-2228-3057, Fax: +82-2-364-7113, E-mail: wychung@yuhs.ac, ORCID: Won-Yoon Chung, http://orcid.org/0000-0001-8428-9005

Copyright (c) 2016 Korean Society of Cancer Prevention

(c) This is an Open Access article distributed under the terms of the Creative Commons Attribution Non-Commercial License (http://creativecommons.org/licenses/by-nc/4.0) which permits unrestricted non-commercial use, distribution, and reproduction in any medium, provided the original work is properly cited. 
Traditional medicine plants are being considered as promising research materials in drug discovery. ${ }^{11}$ Forsythia koreana, a flowering plant in the family Oleaceae, is widely cultivated in South Korea and used to treat inflammatory diseases in Chinese medicine. $^{12} E$ koreana extract has various pharmacological properties including antioxidant, anti-bacterial, and anti-allergic activities. $^{13-15}$ In particular, $F$ koreana fruit extract inhibits COX-2-mediated prostaglandin $\mathrm{E}_{2}$ production and nitric oxide synthase, indicating anti-inflammatory effects. ${ }^{16,17}$ Recent studies reported that the bioactive compounds from $F$ koreana fruit extract have cytotoxicity against Michigan Cancer Foundation (MCF)-7 human non-metastatic breast cancer cells via activation of caspase- 8 and induction of the DR4/5 death receptors. ${ }^{18}$ However, the effect of $F$ koreana extracts on metastatic breast cancer cells and osteoclasts, which are target cells for blocking cancer-induced bone destruction, remains unproved.

The aim of this study is to evaluate the protective potential of $F$ koreana extracts on breast cancer cell-induced bone destruction. We investigated the effects of $F$ koreana extracts on the migration and invasion of breast cancer cells and the formation and activation of osteoclasts.

\section{MATERIALS AND METHODS}

\section{Materials}

F. koreana Nakai branches and leaves were extracted with methanol and concentrated. Fruit extract was provided by Korea National Research Resource Bank. The extracts were dissolved with dimethyl sulfoxide (DMSO). Dulbecco's modified Eagle medium (DMEM), FBS, Dulbecco's PBS, $\alpha$-minimum essential medium ( $\alpha$-MEM), and antibiotics were purchased from Gibco BRL (Grand Island, NY, USA). Recombinant mouse soluble RANKL (sRANKL) and macrophage-colony stimulating factor (M-CSF) were obtained from $R \& D$ Systems (Minneapolis, MN, USA). Histopaque-1083, MTT, DMSO were purchased from Sigma-Aldrich (St. Louis, MO, USA).

\section{Animal}

Four-week old male Institute of Cancer Research (ICR) mice were purchased from the Nara Biotech (Pyeongtaek, Korea). The mice were provided free access to a commercial rodent chow and tap water ad libritum, and housed under specific pathogen-free conditions with a 12 hours light/dark cycle at $22^{\circ} \mathrm{C} \pm 2^{\circ} \mathrm{C}$. All animal experimental procedures were conducted in compliance with the guidelines and regulations for the use and care of animals established by Yonsei University College of
Dentistry (Seoul, Korea).

\section{Cell cultures}

Human mammary carcinoma cell line MDA-MB-231 was obtained from the Korea Cell Line Bank (Seoul, Korea) and the cells were maintained in DMEM supplemented with 10\% FBS and $1 \%$ antibiotic-antimycotic mixture at $37^{\circ} \mathrm{C}$. Mouse bone marrow-derived macrophages (BMMs) were isolated from tibiae of 4-week-old male ICR mice and cultured in a $\alpha$-MEM containing $10 \% \mathrm{FBS}, 30 \mathrm{ng} / \mathrm{mL} \mathrm{M}-\mathrm{CSF}$, and $1 \%$ antibiotic-antimycotic mixture at $37^{\circ} \mathrm{C}$. All of the cells were incubated in a humidified atmosphere of $5 \% \mathrm{CO}_{2}$.

\section{Cell viability}

MDA-MB-231 cells $\left(1 \times 10^{3}\right.$ cells/well $)$ were seeded into a 96-well plate with DMEM containing 10\% FBS and the attached cells were incubated in serum-free media with the various concentrations of $F$. koreana fruit, branch or leaf extract for 24 hours. BMM cells $\left(5 \times 10^{4}\right.$ cells) were treated with the indicated concentration of $F$ koreana fruit, branch or leaf extract in $\alpha$-MEM containing 10\% FBS and $30 \mathrm{ng} / \mathrm{mL}$ M-CSF for 5 days with replacement to fresh medium every second day. The cell viability was measured using an MTT assay. ${ }^{19}$

\section{Cell migration and invasion}

Migration assay was performed in 24-well transwell chamber ( $8 \mathrm{~mm}$ pore size; Corning Costar, Cambridge, MA, USA) coated with $10 \%(\mathrm{w} / \mathrm{v})$ gelatin. Invasion assay was performed using 24-well transwell chamber coated with $10 \%(\mathrm{w} / \mathrm{v})$ gelatin and $1 \mathrm{mg} / \mathrm{mL}$ Matrigel (BD Biosciences, Palo Alto, CA, USA). MDA-MB-231 cells $\left(5 \times 10^{4}\right.$ cells $\left./ 200 \mu \mathrm{L}\right)$ were incubated in serum-free DMEM containing $F$ koreana fruit extract at the indicated concentrations and/or TGF- $\beta 1$ (10 ng/mL) in the upper part of a transwell chamber for 6 hours or 24 hours. The lower part of chamber were added with $600 \mu \mathrm{L}$ DMEM containing $5 \%$ FBS and $F$ koreana fruit extract at the indicated concentrations. The migrated or invaded cells to the lower surface of the membrane were fixed with $70 \%$ methanol, stained with hematoxylin, and then counted using a Zeiss Axio imager microscope (Zeiss, Oberkochen, Germany).

\section{Osteoclast formation}

BMMs $\left(5 \times 10^{4}\right.$ cells/well) were seeded in 96-well plate and cultured with $\alpha$-MEM containing $10 \%$ FBS, M-CSF (30 ng/mL), sRANKL $(100 \mathrm{ng} / \mathrm{mL})$, and the various concentrations of $F$ koreana extracts for 5 days. The medium was replaced with fresh medium every 2 days. The cells were fixed with $3.7 \%(\mathrm{v} / \mathrm{v})$ 
formaldehyde and stained using the Acid Phosphatase Leukocyte kit (Sigma-Aldrich). The multinucleated tartrate-resistant acid phosphatase-positive cells ( $\geq 3$ nuclei) were counted $(\times 100$, magnification).

\section{Pit formation}

BMMs $\left(5 \times 10^{4}\right.$ cells/well) were seeded in an Osteo assay plate (Corning, Cambridge, MA, USA) and cultured in $\alpha$-MEM containing 10\% FBS, M-CSF (30 ng/mL), and sRANKL (100 ng/mL) for 5 days to induce osteoclastogenesis. The cells were then treated with the various concentrations of $F$ koreana extracts for additional 2 days. The media were collected to measure the activities of MMPs and cathepsin $\mathrm{K}$ and the adherent cells were removed using $5 \%$ sodium hypochlorite solution. The resorbed pits were observed under light microscope $(\times 100$, magnification).

\section{Activities of matrix metalloproteinases and cathepsin $\mathrm{K}$}

MDA-MB-231 cells $\left(5 \times 10^{5}\right.$ cells/dish) were plated in $60 \mathrm{~mm}$ culture dishes and incubated with indicated concentrations of $F$ koreana fruit extract in DMEM containing $1 \%$ FBS and TGF- $\beta 1$ (10 $\mathrm{ng} / \mathrm{mL}$ ) for 24 hours. The culture media of MDA-MB-231 cells and
RANKL-induced osteolcasts were collected by centrifugation at $200 \times g$ for 5 minutes. The activities of MMP- 2 and MMP-9 were detected by gelatin zymography and cathepsin $\mathrm{K}$ activity was measured with commercially available kit as described previously. $^{20}$

\section{Statistics analysis}

Data were expressed as mean $\pm \mathrm{SE}$ of three independent experiments. Statistical analysis was performed with a one-way ANOVA and Student's $t$-test to express the difference between the two groups. Results with values of $P<0.05$ were considered statistically significant. Statistical analysis was performed with SPSS statistical software ver. 21 (IBM Co., Endicott, NY, USA).

\section{RESULTS}

\section{Forsythia koreana extracts inhibited the invasion} of MDA-MB-231 human breast cancer cells

We first investigated the effects of $E$ koreana fruit, branch, and leaf extracts on the viability of MDA-MB-231 metastatic human breast cancer cells. The fruit extract inhibited the cell viability by $15 \%$ at $40 \mu \mathrm{g} / \mathrm{mL}$ and by $33 \%$ at $100 \mu \mathrm{g} / \mathrm{mL}$ (Fig. 1A) but the branch (Fig. 1B) and leaf (Fig. 1C) extracts did not affect. Next, we found
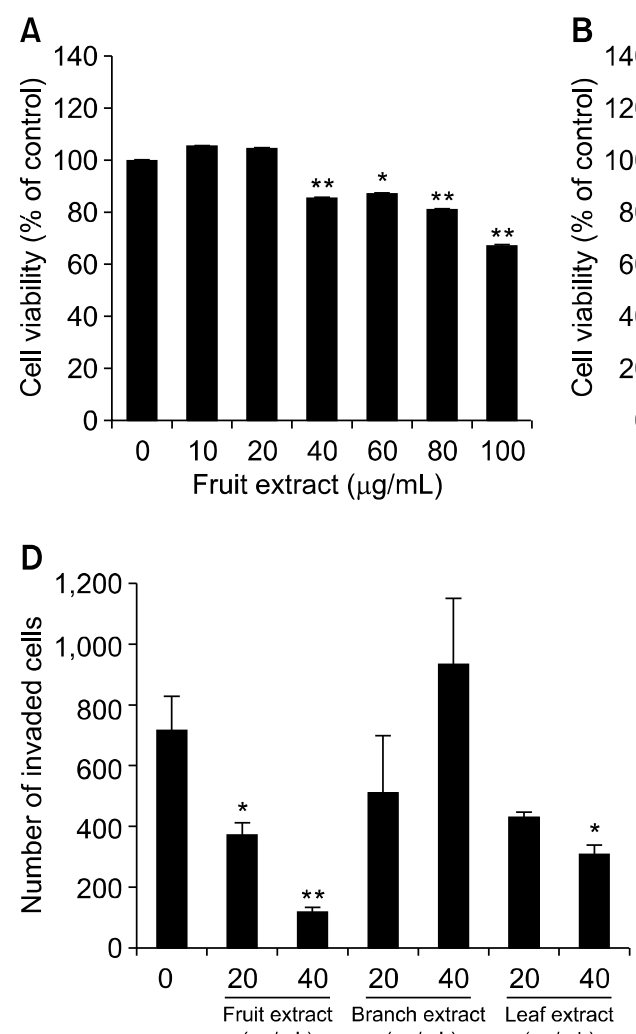

$(\mu \mathrm{g} / \mathrm{mL})$
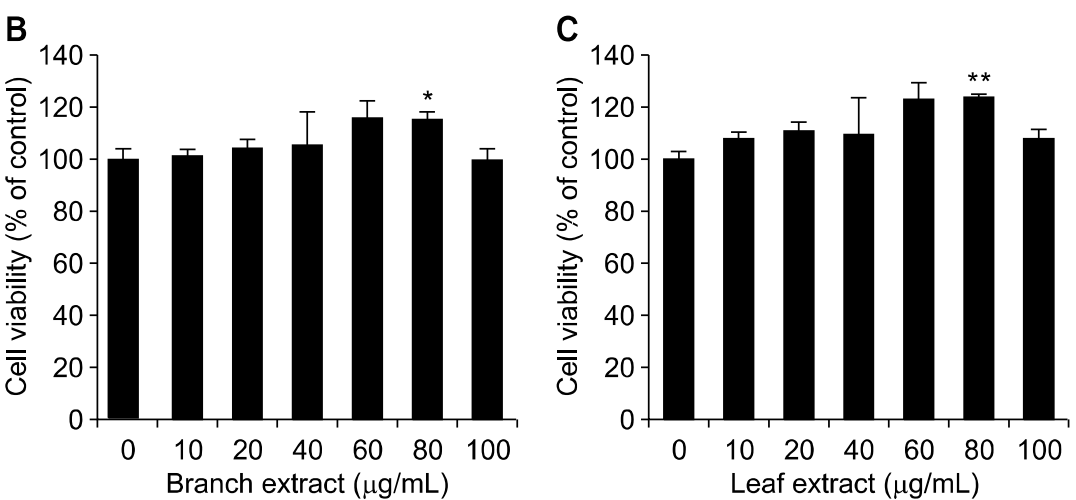

Figure 1. The effects of Forsythia koreana extracts on the viability and invasion of MDA-MB-231 cells. MDA-MB-231 cells were treated with indicated concentrations of $F$. koreana (A) fruit, (B) branch, and (C) leaf extracts for 24 hours. The cell viability was determined by an MTT assay. (D) MDA-MB-231 cells were placed on the Matrigel-coated upper chambers with serum-free Dulbecco's modified Eagle medium (DMEM) containing $F$. koreana extracts. The lower chambers were filled with $600 \mu \mathrm{L}$ of 5\% FBS-DMEM and F. koreana extracts. Twenty-four hours later, the invaded cells were counted. Data are expressed mean $\pm \mathrm{SE} . * P<0.05,{ }^{*} * P<0.01$ vs. untreated cells. 




that $F$ koreana fruit and leaf extracts significantly reduced the invasion of MDA-MB-231 cells by $48 \%$ and $41 \%$ at $20 \mu \mathrm{g} / \mathrm{mL}$ and $84 \%$ and $58 \%$ at $40 \mu \mathrm{g} / \mathrm{mL}$, respectively (Fig. $1 \mathrm{D}$ ).

2. Forsythia koreana fruit extract attenuated the TGF- $\beta 1$-induced migration and invasion of MDAMB-231 cells

TGF- $\beta 1$ plays a critical role in the migration and invasion of breast cancer cells. ${ }^{21,22}$ MMPs are closely associated with cancer invasion and metastasis. ${ }^{23}$ The treatment with $F$ koreana fruit extract decreased the migration ( $\mathrm{IC}_{50}=50.6 \mu \mathrm{g} / \mathrm{mL}$; Fig. $2 \mathrm{~A}$ ) and invasion ( $\mathrm{IC}_{50}=22.5 \mu \mathrm{g} / \mathrm{mL}$; Fig. $2 \mathrm{~B}$ ) of MDA-MB-231 cells by $75 \%$ and $92 \%$ at $80 \mu \mathrm{g} / \mathrm{mL}$, respectively. TGF- $\beta 1$-induced migration $\left(\mathrm{IC}_{50}=49.5 \mu \mathrm{g} / \mathrm{mL}\right.$; Fig. $\left.2 \mathrm{~A}\right)$ and invasion ( $\mathrm{IC}_{50}=40.9 \mu \mathrm{g} / \mathrm{mL}$; Fig. 2B) were also reduced by $F$ koreana fruit extract by $79 \%$ and $82 \%$ at $80 \mu \mathrm{g} / \mathrm{mL}$, respectively. In addition, the fruit extract suppressed the proteolytic activities of MMP- 2 and MMP-9 in the culture media of MDA-MB-231 cells with or without TGF- $\beta 1$ (Fig. 2C).

\section{Forsythia koreana extracts blocked the receptor activator of nuclear factor kappa-B ligand-induced osteoclast formation}

Bone loss induced by metastasis of breast cancer is caused by excessive osteoclasts. ${ }^{5}$ The viability of BMMs as osteoclast precursors was not reduced by the treatment with $F$ koreana fruit (Fig. 3A), branch (Fig. 3B) or leaf (Fig. 3C) extracts for 5 days. RANKL-induced osteoclast formation was significantly decreased by $24 \%, 58 \%$, and $92 \%$ at $10 \mu \mathrm{g} / \mathrm{mL}$ and $79 \%, 95 \%$, and $100 \%$ at 20 $\mu \mathrm{g} / \mathrm{mL}$ of the fruit, branch, and leaf extracts, respectively (Fig. 3D).

\section{Forsythia koreana extracts suppressed the bone- resorbing activity of mature osteoclasts}

Figure 2. The effects of Forsythia koreana fruit extract on TGF- $\beta 1$-induced migration and invasion of MDA-MB-231 cells. (A) MDA-MB-231 cells were placed on the upper chambers with serum-free Dulbecco's modified Eagle medium (DMEM) containing $F$. koreana fruit extract and TGF- $\beta 1(10 \mathrm{ng} / \mathrm{mL})$. The lower chambers were filled with $600 \mu \mathrm{L}$ of 5\% FBS-DMEM containing $F$. koreana fruit extract. The cells were incubated for 6 hours. (B) MDA-MB-231 cells were placed on the Matrigel-coated upper chambers with serum-free DMEM containing $F$. koreana fruit extract and TGF- $\beta 1(10 \mathrm{ng} / \mathrm{mL})$. The lower chambers were filled with $600 \mu \mathrm{L}$ of 5\% FBS-DMEM containing $F$. koreana fruit extracts. The cells were incubated for 24 hours. The migrated or invaded cells were fixed, stained, and counted as a described in Materials and Methods. Data are expressed mean $\pm \mathrm{SE} .{ }^{\#} P<0.05,{ }^{\# \#} P<0.01$ vs. untreated cells, $* P<0.05$, $* * P<0.01$ vs. MDA-MB-231 cells with TGF- $\beta 1$ alone. (C) MDA-MB-231 cells were cultured with $F$. koreana fruit extract and $1 \%$ FBS-DMEM in the absence or presence of TGF- $\beta 1(10 \mathrm{ng} / \mathrm{mL})$ for 24 hours. The levels of matrix metalloproteinase (MMP)-2 and MMP-9 in the collected medium were examined using gelatin zymography. The clear bands indicate the activities of MMPs.

In bone mimetic material-coated plates, three $E$ koreana extracts substantially inhibited the formation of osteoclast-mediated resorption pits (Fig. 4A). In gelatin zymography, F koreana branch extract suppressed the activities of MMP-2 and MMP-9 derived from RANKL-induced osteoclasts but the fruit and leaf extracts did not show noticeable inhibition (Fig. 4B). In addition, the cathepsin $\mathrm{K}$ activities induced by RANKL stimulation were significantly decreased by the treatment with $E$ koreana fruit, branch, and leaf extracts by $67 \%, 80 \%$, and $78 \%$ at $40 \mu \mathrm{g} / \mathrm{mL}$, respectively (Fig. 4C).

\section{DISCUSSION}

In the present study to investigate whether $F$ koreana extracts 



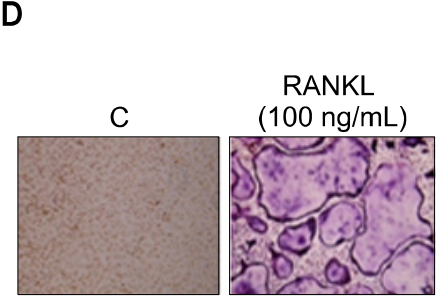

RANKL (100 ng/mL) + branch extract $(\mu \mathrm{g} / \mathrm{mL})$

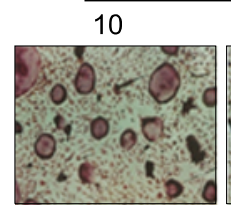

20

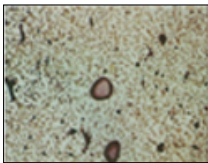

RANKL (100 ng/mL) + fruit extract $(\mu \mathrm{g} / \mathrm{mL})$

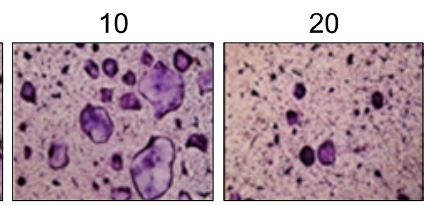

RANKL (100 ng/mL) + leaf extract $(\mu \mathrm{g} / \mathrm{mL})$

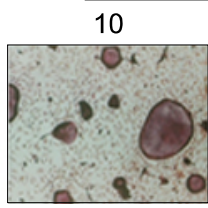

20

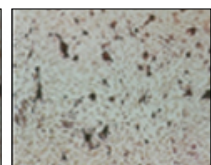



RANKL $(100 \mathrm{ng} / \mathrm{mL})+$ extract $(\mu \mathrm{g} / \mathrm{mL})$

Figure 3. The effects of Forsythia koreana extracts on receptor activator of nuclear factor kappa-B ligand (RANKL)-induced osteoclast formation. The bone marrow-derived macrophages (BMMs) were treated with M-CSF (30 ng/mL) and indicated concentrations of F. koreana (A) fruit, (B) branch, or (C) leaf extracts for 5 days. The cell viability was determined by an MTT assay. Data are expressed as the mean \pm SE. $* P<0.05$, ${ }^{* *} P<0.001$ vs. untreated cells. (D) The BMMs were cultured in $\alpha$-minimum essential medium with $\mathrm{M}-\mathrm{CSF}(30 \mathrm{ng} / \mathrm{mL}), \mathrm{RANKL}(100 \mathrm{ng} / \mathrm{mL})$ and F. koreana extracts at the indicated concentrations for 5 days. The cells were detected by tartrate-resistant acid phosphatase staining and osteoclasts were counted ( $\times 100$, magnification). Data are expressed as the mean $\pm \mathrm{SE} .{ }^{\#} P<0.05$ vs. BMMs without RANKL (C, control). $* P<$ $0.05, * * P<0.001$ vs. BMMs with RANKL alone.

have preventive potential on breast cancer-induced bone destruction, $F$ koreana fruit extract suppressed the viability of MDA-MB-231 metastatic breast cancer cells but did not show high cytotoxic effect. The fruit and leaf extracts at the non-cytotoxic concentrations considerably inhibited the invasiveness of MDA-MB-231 cells. Cancer cells interact with many growth factors and cytokines during progression and metastasis. ${ }^{24,25}$ Among them, TGF- $\beta 1$ enhances the metastatic ability of breast cancer cells through stimulation of epithelial-mesenchymal transition processes and the activation of the MMPs, which are required for cancer cells to degrade physical barriers during local expansion, intravasation, extravasation, and invasion at a distant location. ${ }^{8.26}$ TGF- $\beta 1$ modulates the homeostasis between MMPs and MMP inhibitors in highly invasive breast cancer cells. ${ }^{27}$ In our data, $F$ koreana fruit extract, with weak cytotoxic activity but remarkable anti-invasive activity in MDA-MB-231 cells, inhibited TGF- $\beta 1$-in- duced migration, invasion, and activities of MMP-2 and MMP-9. These results demonstrate the anti-metastatic potential of $F$ koreana fruit extract against metastatic breast cancer cells.

In breast cancer patients with bone metastasis, osteoclast formation, and activation were abnormally increased. ${ }^{2}$ Several enzymes such as cathepsin $\mathrm{K}$ and MMPs were released from mature osteoclasts and these hydrolytic enzymes digest organic components of the bone matrix and promote bone resorption. ${ }^{28}$ Thus, many researchers have paid much attention to osteoclast-targeting new agents for the treatment of patients with bone metastasis of breast cancer. ${ }^{9.10}$ Recent studies suggest that breast cancer induced-bone destruction can be prevented by controlling RANKL-induced osteoclast formation and activities of these enzymes. ${ }^{20.29 \cdot 31}$ In our study, $F$ koreana fruit, branch, and leaf extracts did not show cytotoxicity at less than $100 \mu \mathrm{g} / \mathrm{mL}$ and significantly inhibited the RANKL-induced formation of osteoclasts 
A



$\operatorname{RANKL}(100 \mathrm{ng} / \mathrm{mL})+$ extract $(\mu \mathrm{g} / \mathrm{mL})$
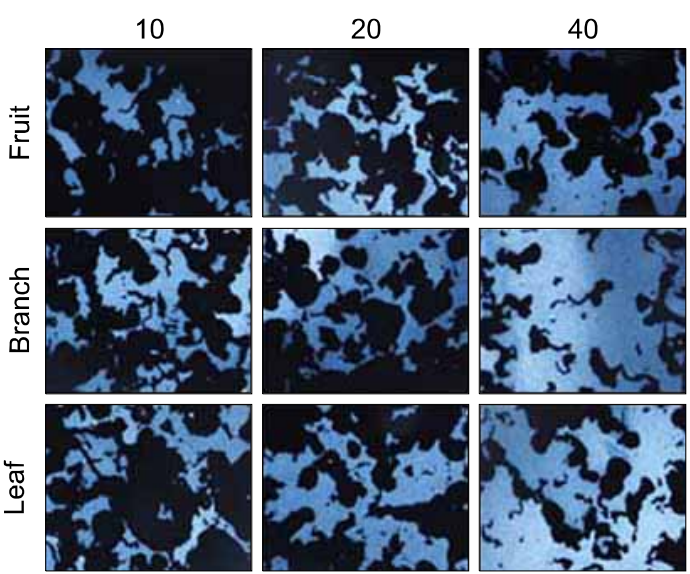

C

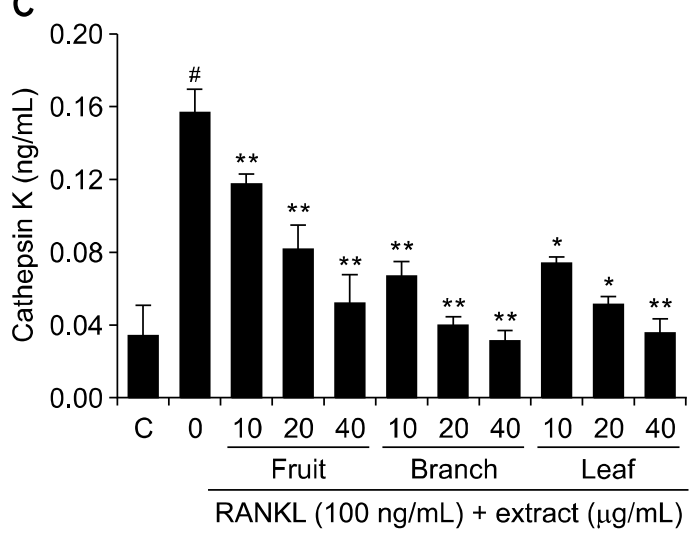

B

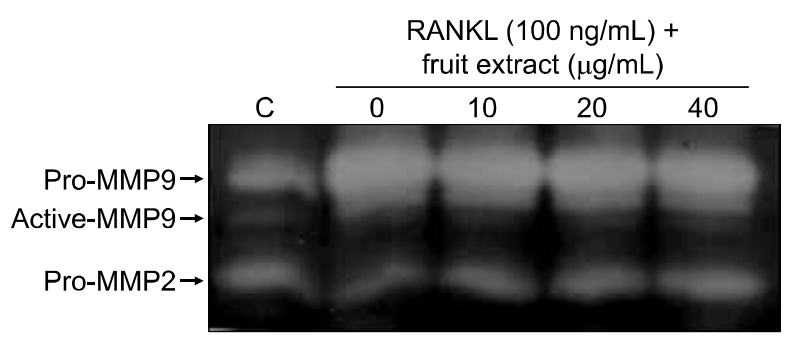

RANKL (100 ng/mL) + branch extract $(\mu \mathrm{g} / \mathrm{mL})$

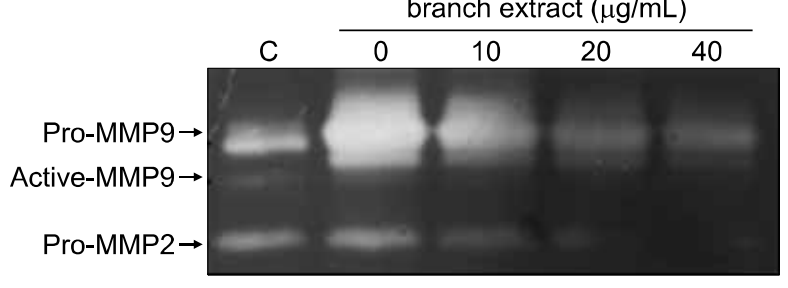

RANKL (100 ng/mL) + leaf extract $(\mu \mathrm{g} / \mathrm{mL})$



Figure 4. The effects of Forsythia koreana extracts on bone resorbing-activity of osteoclasts. Bone marrow-derived macrophages (BMMs) were seeded in Osteo assay plate and treated with M-CSF $(30 \mathrm{ng} / \mathrm{mL})$ and receptor activator of nuclear factor kappa-B ligand (RANKL) (100 ng/mL) for 5 days. After induction of osteoclasts, the cells were treated with F. koreana extracts for an additional 2 days. (A) The resorption pits were observed under a light microscopy $(\times 100$, magnification). (B) The activities of matrix metalloproteinase (MMP)-2 and MMP-9 in cultured media of osteoclasts were detected by gelatin zymography as described in Materials and Methods. (C) Cathepsin K levels in cultured media of osteoclasts were measured using the Sensizyme Cathepsin $\mathrm{K}$ activity kit. Data are expressed as the mean \pm SE. ${ }^{\#} P<0.05$ vs. BMMs without RANKL (C, control). $* P<0.05, * * P<0.001$ vs. BMMs with RANKL alone.

and resorption pits at $20 \mu \mathrm{g} / \mathrm{mL}$. Moreover, F. koreana branch extract, rather than the fruit and leaf extracts, substantially inhibited the secreted levels of MMP-2 and MMP-9. Three extracts decreased the release of osteoclast-derived cathepsin $\mathrm{K}$ into the culture media. These results indicate that $E$ koreana extracts may prevent breast cancer-related bone resorption by attenuating RANKL-induced osteoclast formation and activation.

Taken together, $E$ koreana fruit and leaf extracts have anti-metastatic potential on breast cancer cells and $F$. koreana extracts have anti-osteoclastogenic and anti-bone-resorbing activities. Therefore, E. koreana extracts can target both breast cancer cells and osteoclasts, thereby they may be promising agents for prevention of cancer-mediated bone loss and the related skeletal diseases.

\section{ACKNOWLEDGMENTS}

This work was carried out with the support of "Cooperative 
Research Program for Agriculture Science \& Technology Development (Project No. PJ011578)" Rural Development Administration, Republic of Korea.

\section{CONFLICTS OF INTEREST}

No potential conflicts of interest were disclosed.

\section{REFERENCES}

1. Mundy GR. Metastasis to bone: causes, consequences and therapeutic opportunities. Nat Rev Cancer 2002;2:584-93.

2. Kingsley LA, Fournier PG, Chirgwin JM, Guise TA. Molecular biology of bone metastasis. Mol Cancer Ther 2007;6:2609-17.

3. David Roodman G. Role of stromal-derived cytokines and growth factors in bone metastasis. Cancer 2003;97(3 Suppl):733-8.

4. Yin JJ, Pollock CB, Kelly K. Mechanisms of cancer metastasis to the bone. Cell Res 2005;15:57-62.

5. Suva LJ, Washam C, Nicholas RW, Griffin RJ. Bone metastasis: mechanisms and therapeutic opportunities. Nat Rev Endocrinol 2011;7:208-18.

6. Theriault RL, Theriault RL. Biology of bone metastases. Cancer Control 2012;19:92-101.

7. Hiraga T, Myoui A, Hashimoto N, Sasaki A, Hata K, Morita Y, et al. Bone-derived IGF mediates crosstalk between bone and breast cancer cells in bony metastases. Cancer Res 2012;72:4238-49.

8. Guise TA, Chirgwin JM. Transforming growth factor-beta in osteolytic breast cancer bone metastases. Clin Orthop Relat Res 2003;(415 Suppl):S32-8.

9. Roodman GD. Bone-breaking cancer treatment. Nat Med 2007; 13:25-6.

10. Coleman R, Gnant M, Morgan G, Clezardin P. Effects of bone-targeted agents on cancer progression and mortality. J Natl Cancer Inst 2012;104:1059-67.

11. Cragg GM, Newman DJ. Natural products: a continuing source of novel drug leads. Biochim Biophys Acta 2013;1830:3670-95.

12. Bae KH. The medicinal plants of Korea. Seoul, Kyohak Publishing, pp 399, 2000.

13. Yang XN, Khan I, Kang SC. Chemical composition, mechanism of antibacterial action and antioxidant activity of leaf essential oil of forsythia koreana deciduous shrub. Asian Pac J Trop Med 2015:8:694-700

14. Choi IY, Moon PD, Koo HN, Myung NY, Kim SJ, Lee JH, et al. Observations of forsythia koreana methanol extract on mast cell-mediated allergic reactions in experimental models. In Vitro Cell Dev Biol Anim 2007;43:215-21.

15. Kitagawa S, Nishibe S, Baba H. Studies on the Chinese crude drug "forsythiae fructus". VIII. On isolation of phenylpropanoid glycosides from fruits of Forsythia koreana and their antibacterial activity. Yakugaku Zasshi 1987;107:274-8.

16. Lim H, Lee JG, Lee SH, Kim YS, Kim HP. Anti-inflammatory activity of phylligenin, a lignan from the fruits of Forsythia koreana, and its cellular mechanism of action. J Ethnopharmacol 2008;118:113-7.

17. Lee JY, Cho BJ, Park TW, Park BE, Kim SJ, Sim SS, et al. Dibenzylbutyrolactone lignans from Forsythia koreana fruits attenuate lipopolysaccharide-induced inducible nitric oxide synthetase and cyclooxygenase-2 expressions through activation of nuclear factor-kb and mitogen-activated protein kinase in RAW264.7 cells. Biol Pharm Bull 2010;33:1847-53.

18. Hawas UW, Gamal-Eldeen AM, El-Desouky SK, Kim YK, Huefner A, Saf R. Induction of caspase- 8 and death receptors by a new dammarane skeleton from the dried fruits of Forsythia koreana. Z Naturforsch C 2013;68:29-38.

19. Lee SK, Park KK, Kim KR, Kim HJ, Chung WY. Isoliquiritigenin inhibits metastatic breast cancer cell-induced receptor activator of nuclear factor kappa-B ligand/osteoprotegerin ratio in human osteoblastic cells. J Cancer Prev 2015;20:281-6.

20. Park SY, Kim HJ, Kim KR, Lee SK, Lee CK, Park KK, et al. Betulinic acid, a bioactive pentacyclic triterpenoid, inhibits skeletal-related events induced by breast cancer bone metastases and treatment. Toxicol Appl Pharmacol 2014:275:152-62.

21. Ganapathy V, Ge R, Grazioli A, Xie W, Banach-Petrosky W, Kang Y, et al. Targeting the transforming growth factor-beta pathway inhibits human basal-like breast cancer metastasis. Mol Cancer 2010;9:122.

22. Moustakas A, Heldin P. TGF $\beta$ and matrix-regulated epithelial to mesenchymal transition. Biochim Biophys Acta 2014;1840:2621-34.

23. Fingleton B. Matrix metalloproteinases: roles in cancer and metastasis. Front Biosci 2006;11:479-91.

24. Dranoff G. Cytokines in cancer pathogenesis and cancer therapy. Nat Rev Cancer 2004:4:11-22.

25. Esquivel-Velázquez $\mathrm{M}$, Ostoa-Saloma $\mathrm{P}$, Palacios-Arreola $\mathrm{MI}$, Nava-Castro KE, Castro JI, Morales-Montor J. The role of cytokines in breast cancer development and progression. J Interferon Cytokine Res 2015:35:1-16.

26. Gialeli C, Theocharis AD, Karamanos NK. Roles of matrix metalloproteinases in cancer progression and their pharmacological targeting. FEBS J 2011;278:16-27.

27. Gomes LR, Terra LF, Wailemann RA, Labriola L, Sogayar MC. TGF- $\beta 1$ modulates the homeostasis between MMPs and MMP inhibitors through $\mathrm{p} 38$ MAPK and ERK1/2 in highly invasive breast cancer cells. BMC Cancer 2012;12:26.

28. Boyle WJ, Simonet WS, Lacey DL. Osteoclast differentiation and activation. Nature 2003:423:337-42.

29. Le Gall C, Bonnelye E, Clézardin P. Cathepsin K inhibitors as treatment of bone metastasis. Curr Opin Support Palliat Care 2008:2:218-22.

30. Jun AY, Kim HJ, Park KK, Son KH, Lee DH, Woo MH, et al. Tetrahydrofurofuran-type lignans inhibit breast cancer-mediated bone destruction by blocking the vicious cycle between cancer cells, osteoblasts and osteoclasts. Invest New Drugs 2014:32:1-13.

31. Kim KR, Kim HJ, Lee SK, Ma GT, Park KK, Chung WY. 15-deoxy- $\delta 12,14$-prostaglandin $j 2$ inhibits osteolytic breast cancer bone metastasis and estrogen deficiency-induced bone loss. PLoS One 2015;10:e0122764. 